\title{
INTERNACIONALIZAÇÃO DE ATIVIDADES DE PESQUISA E DESENVOLVIMENTO DAS EMPRESAS TRANSNACIONAIS análise da inserção das filliais brasileiras
}

Célio Hiratuka

Resumo: O presente trabalho busca analisar o processo de internacionalização das atividades de P\&D das Empresas Transnacionais, a partir das informações das corporações com sede nos Estados Unidos. Procura-se verificar como essas empresas distribuem seus gastos em P\&D nos países em desenvolvimento, analisando comparativamente os países da Ásia e da América Latina, com ênfase no caso brasileiro.

Palavras-chave: Pesquisa e desenvolvimento. Empresas transnacionais. Globalização.

Abstract: The aim of this paper is to analyse the internationalisation of Research and Development activities carried by the Transnational Corporations. Based on the information of Transnational Corporations from United States provided by the Bureou of Economic Analisys, the paper try to assess how these corporations allocate its R\&D expenses inf foreign countries, comparing the the role of Asia and Latin America affiliates, with special reference to Brazilian affiliates.

Key words: Research and development. Transnational corporations. Globalization.

$\mathrm{D}$ epois de um período de retração em decorrência da crise ocorrida nos anos 80 , a economia brasileira voltou a receber volumes significativos de Investimento Direto Estrangeiro - IDE, a partir da década de 90, em especial em sua segunda metade. A participação brasileira no total dos fluxos mundiais passou de cerca de 1\%, no período 1990-95, para 2,9\%, entre 1996 e 2001, atingindo uma média anual de aproximadamente US\$ 23,7 bilhões.

Como resultado, o grau de internacionalização da estrutura produtiva, que já era alto, aumentou ainda mais. Em 1996, as empresas majoritariamente estrangeiras respondiam por $27 \%$ do total do faturamento da indústria, passando para $42 \%$, em 2000. Em termos de comércio exterior, também verificou-se elevação significativa na participação das empresas estrangeiras majoritárias no total exportado: com uma participação de $31 \%$, em 1995 , as filiais passaram a responder por $41 \%$ do total exportado pelo Brasil.

Dado esse aumento da importância das filiais de empresas transnacionais - ETNs na estrutura produtiva da economia brasileira, torna-se fundamental a questão de como essas empresas têm conduzido suas atividades de Pesquisa e Desenvolvimento - P\&D no país e contribuído para a evolução do sistema nacional de inovação. Em especial quando se considera que os gastos de $P \& D$ em relação ao PIB na economia brasileira têm se mantido estagnados em níveis relativamente modestos $(0,97 \% \mathrm{em}$ 2000) e majoritariamente financiados com recursos públicos $(56 \%$ do total contra $42 \%$ financiado pelo setor empresarial), de acordo com dados do Ministério de Ciência e Tecnologia. 
Outro fator importante é que o aumento da presença de ETNs na economia brasileira ocorre em um momento em que essas empresas vêm implementando um processo intenso de reorganização das suas atividades internacionais. Considerando a globalização das atividades tecnológicas das ETNs, vários autores destacam que, embora a internacionalização dos laboratórios de $\mathrm{P} \& \mathrm{D}$ ocorra em ritmo muito inferior ao verificado na atividade de produção e comercialização, esses laboratórios estariam também mais integrados globalmente, cumprindo a função não apenas de adaptar produto e processo aos locais de implantação, mas também de alavancar capacitações tecnológicas, buscando ativos intangíveis imóveis internacionalmente e que poderiam ser mais bem aproveitados por meio da instalação de atividades de $P \& D$ no exterior.

Potencialmente, esse processo poderia, de acordo com alguns autores, representar um aprofundamento das atividades de P\&D nos países de implantação das filiais, aumentando a possibilidade de efeitos positivos de transbordamento em relação a atividades simples de adaptação. Em especial, esse efeito seria importante nos países em desenvolvimento dada a carência em termos de capacitação tecnológica do sistema empresarial local. Entretanto, outros autores ressaltam que o processo de internacionalização tem ficado concentrado nos países centrais, mantendo as nações em desenvolvimento ainda marginalizadas do processo de globalização das atividades inovativas.

Este artigo busca recolher evidências sobre a internacionalização das atividades de P\&D das grandes corporações, a partir dos dados das ETN com sede nos Estados Unidos. O objetivo do trabalho é não apenas analisar as características das atividades internacionais de P\&D das filiais de empresas norte-americanas nos países em desenvolvimento, comparando em especial a América Latina e a Ásia, mas também ressaltar o papel e a inserção das filiais instaladas no Brasil.

Além desta introdução, o presente trabalho está organizado em mais três seções. Na primeira, são tecidas breves considerações sobre o processo de globalização das atividades de $\mathrm{P} \& \mathrm{D}$ a partir da literatura internacional. $\mathrm{Na}$ segunda seção, são analisados os dados sobre P\&D das filiais de ETN dos Estados Unidos, comparando a inserção dos países desenvolvidos e em desenvolvimento e, nestes últimos, separando os países da Ásia e da América Latina, com ênfase no Brasil. A terceira seção apresenta as considerações finais do artigo.

\section{ETN E GLOBALIZAÇÃO DAS ATIVIDADES DE P\&D}

A literatura sobre as atividades de P\&D das corporações multinacionais tem destacado tanto os fatores que levam à centralização das atividades mais importantes de $\mathrm{P} \& \mathrm{D}$ no país de origem quanto aqueles que poderiam contribuir para que essa atividade fosse efetivamente deslocada para o exterior. ${ }^{1}$

Pearce (1999) destaca três fatores que levariam as grandes corporações a manterem as atividades de $P \& D$ centralizadas no país de origem. O primeiro seria a existência de economias de escala em P\&D, associadas à utilização de equipamentos, laboratórios e equipes de pesquisa. Ou seja, a instalação de um segundo centro de pesquisa no exterior não seria economicamente viável enquanto os recursos indivisíveis destinados ao laboratório central não estivessem plenamente utilizados. O segundo fator seria o fato de que as atividades tecnológicas e de inovação teriam o benefício de interagir com outros elementos do sistema de inovação do país de origem, como centros de pesquisa, fornecedores, comunidade científica, etc. A reprodução dessas vantagens no exterior demandaria esforços elevados e, principalmente, um tempo prolongado. Por fim, o terceiro fator estaria associado aos custos de coordenação e controle relacionados à descentralização de uma atividade estratégica como a P\&D. Além do risco de perda de foco dos programas definidos como prioritários, existiria também o risco de difusão indesejada das tecnologias desenvolvidas na passagem de uma estrutura centralizada para outra mais dispersa.

Apesar da influência desses fatores, os elementos que favorecem a maior internacionalização das atividades de P\&D vêm ganhando força nos anos recentes. O estudo de Cantwell e Janne (2000) mostra o aumento da tendência à internacionalização a partir da análise das patentes depositadas nos Estados Unidos por um conjunto de 748 ETNs. Enquanto no período 1977-79, 11,1\% dessas patentes resultavam de pesquisas realizadas fora do país de origem da corporação, entre 1987 e 1995, essa proporção teria se elevado para $16,2 \%$.

Entre os fatores explicativos para um maior deslocamento das atividades de P\&D para fora do país de origem, estariam a própria internacionalização das vendas e a procura de novos mercados por parte das ETNs. Ou seja, a internacionalização tecnológica estaria associada à maior internacionalização produtiva buscada pelas grandes corporações, ocorrendo, entretanto, em ritmo e intensidade muito menores. É importante ressaltar que, nessa in- 
terpretação, o aumento das atividades de $\mathrm{P} \& \mathrm{D}$ no exterior refletiria apenas a intensificação de uma tendência que vem desde o pós-guerra, uma vez que as atividades tecnológicas no exterior teriam basicamente um papel de suporte à exploração de mercados externos, associado à necessidade de adaptar produtos e processos às especificidades dos mercados de implantação. A internacionalização cumpriria fundamentalmente a função de garantir a exploração de vantagens criadas por avanços tecnológicos desenvolvidos no país de origem. Nesse caso, embora as atividades de $\mathrm{P} \& \mathrm{D}$ fossem mais deslocadas para o exterior, seu escopo seria bastante reduzido, mantendose as atividades nucleares no país de origem.

Entretanto, vários autores, como Pearce (1999), Le Bas e Sierra (2002) e Narula e Zanfei (2003), vêm destacando que a internacionalização das atividades tecnológicas das ETNs representaria não apenas um aprofundamento da tendência anterior, em que a internacionalização da P\&D seria meramente reflexo do aumento da internacionalização da produção, mas também uma mudança qualitativa, associada a alterações nas estratégias de operação para acumulação de recursos em nível global, implementada pelas ETNs no período recente.

A desestruturação das condições que haviam garantido o ciclo de crescimento das décadas de 50 e 60 e as mudanças na ordem econômica mundial observadas a partir da crise econômica dos anos 70 nos países centrais impulsionaram um profundo processo de reestruturação nas grandes corporações. No novo ambiente de instabilidade e volatilidade macroeconômica, com baixas taxas de crescimento nos principais países desenvolvidos, as ETNs buscaram reforçar suas vantagens proprietárias, acirrando a concorrência e a disputa por mercados nas várias regiões do globo. A busca de capacitação para inovação em produtos e processos e o aumento em gastos de $\mathrm{P} \& \mathrm{D}$ constituíram um dos aspectos mais importantes, embora não o único, uma vez que foram acompanhados pela estratégia de desenvolvimento de outros ativos intangíveis, como diferenciação de produtos, fixação de marcas e vantagens organizacionais.

No bojo desse processo, a organização internacional das atividades de $P \& D$ sofreu alterações importantes. Além da estratégia tradicional de explorar as vantagens criadas no país de origem em terceiros mercados, Patel e Vega (1999) e Le Bas e Sierra (2002) destacam outros dois tipos de estratégias de internacionalização da P\&D que ganharam importância no período recente.

O primeiro e principal deles seria a estratégia de montar laboratórios de $\mathrm{P} \& \mathrm{D}$ no exterior com o intuito de monitorar os desenvolvimentos científicos e tecnológicos em outros países, que potencialmente poderiam ser complementares às atividades inovativas desenvolvidas no país de origem, reforçando, portanto, as competências já desenvolvidas no interior da corporação. Nesse caso, as vantagens do país de destino, associadas à possibilidade de aproveitamento de externalidades tecnológicas propiciadas pelas firmas e instituições desse país, ocorreriam em áreas semelhantes ao núcleo de competências tecnológicas da ETN no país de origem.

A segunda estratégia, seguida com menos intensidade do que a primeira, seria buscar, em outros países, vantagens e novas capacitações que não estariam disponíveis tão facilmente no país de origem. Portanto, ao contrário da primeira estratégia, o investimento na montagem de laboratórios de $\mathrm{P} \& \mathrm{D}$ no exterior estaria associado a áreas tecnológicas em que existissem fragilidades no sistema nacional de inovação, com o investimento no exterior cumprindo a função justamente de compensar esse aspecto.

Essas estratégias indicariam que as ETNs adotaram um enfoque mais integrado nas suas atividades tecnológicas, com o objetivo não apenas de adaptar produtos aos diferentes mercados, mas também de desenvolver novos produtos e acumular competências associadas às atividades de P\&D no exterior. Nesse contexto, os laboratórios de P\&D fora do país de origem cumpririam uma função muito mais estratégica, abrindo a possibilidade de maior autonomia e, ao mesmo tempo, de maior profundidade nas atribuições desses laboratórios (GERYBADZE; REGER, 1999).

Entretanto, é importante destacar, que, apesar do enfoque mais internacionalizado das atividades de $\mathrm{P} \& \mathrm{D}$, estas continuam sendo bastante seletivas no que se refere às possibilidades de reforçar as competências domésticas ou acumular capacitações consideradas estratégicas, porém, com melhores condições de serem desenvolvidas fora do país de origem. De acordo com Cassiolato et al. (2001), o processo de globalização das atividades tecnológicas das ETNs estaria ocorrendo basicamente entre EUA, Europa e Japão, uma vez que, quando essas corporações buscam interagir com sistemas nacionais de inovação que não os do próprio país de origem, o fazem procurando infra-estruturas de ciência e tecnologia igualmente desenvolvidas. De acordo com Hagedoorn (2002), dos acordos de cooperação tecnológica interfirmas realizados entre 1990 e 1998, apenas $6,8 \%$ teriam ocorrido fora dos países da tríade. Nas nações em desenvolvimento, portanto, o escopo e a profundidade das atividades de P\&D dessas empresas seriam limitados, mantendo o caráter tradicional de adaptação de produtos e processo. 
Se é verdade que a nova fase de internacionalização das atividades de P\&D implementada pelas grandes corporações abre espaço para maior grau de profundidade das atividades tecnológicas realizadas no exterior, aumentando portanto os possíveis impactos positivos dessa internacionalização sobre os países hospedeiros, também é verdade que a seletividade nesse processo cria novas dificuldades para os países em desenvolvimento.

Em primeiro lugar, cabe destacar que a possibilidade de se beneficiar desse processo está diretamente associada à capacidade dos países em desenvolvimento de criarem vantagens de localização não-naturais (DUNNING, 1993) associadas à infra-estrutura de ciência e tecnologia capazes de favorecer o aumento da densidade das atividades de P\&D das filiais. Em segundo lugar, vale lembrar que, mesmo que ocorra investimentos em P\&D por parte das ETNs, a possibilidade de que esses investimentos transbordem para o restante do sistema econômico depende em grande medida da capacidade de absorção do sistema empresarial local. Ou seja, é necessário que haja alguma capacitação tecnológica prévia na estrutura produtiva já existente para que possa ocorrer de fato uma transferência das capacitações tecnológicas desenvolvidas pelas ETNs para a economia dos países.

Esses dois aspectos em conjunto ressaltam a importância da existência de políticas ativas de ciência e tecnológica voltadas não apenas para o desenvolvimento de infra-estrutura, mas também para que essa infraestrutura esteja mais integrada às atividades de aprendizado tecnológico do sistema empresarial, tanto de empresas nacionais quanto estrangeiras. Em especial, nos países onde as ETNs exercem papel relevante no siste- ma produtivo, a política científica e tecnológica deveria estar mais integrada à política industrial e de investimentos estrangeiros, com o intuito de contribuir para o processo de aprendizado e a criação de capacitações tecnológicas locais (LALL, 2000).

$\mathrm{Na}$ próxima seção, busca-se analisar a internacionalização tecnológica das ETNs a partir da evolução dos gastos em P\&D efetuado pelas filiais de empresas com sede nos Estados Unidos. A partir dos dados, procura-se verificar a inserção das filiais brasileiras, em comparação com outros países em desenvolvimento na América Latina e na Ásia.

\section{INTERNACIONALIZAÇÃO DAS ATIVIDADES DE P\&D DAS ETNS DOS ESTADOS UNIDOS E A INSERÇÃO DAS FILIAIS BRASILEIRAS}

Esta seção tem como objetivo analisar a internacionalização das atividades de P\&D das grandes corporações transnacionais norte-americanas no exterior. A partir dos dados coletados pelo Bureau of Economic Analisys nas pesquisas censitárias sobre as operações das ETNs no exterior, as informações foram organizadas e classificadas, separando países desenvolvidos e em desenvolvimento e, neste último grupo, os países da América Latina e da Ásia. Além dos anos de 1989, 1994 e 1999, para os quais estavam disponíveis as pesquisas censitárias, foi analisado também 2002, ano com cobertura amostral e com quantidade menor de informações do que os demais.

A Tabela 1 mostra a evolução da internacionalização das ETNs dos Estados Unidos, tanto em termos das vendas como dos gastos em P\&D. Como é possível perceber,

TABELA 1

Evolução da Internacionalização das Empresas Transnacionais (ETNs), segundo Gastos em P\&D e Vendas Estados Unidos - 1989-2002

\begin{tabular}{|c|c|c|c|c|}
\hline & & & & Em US\$ milhões correntes \\
\hline Gastos e Vendas & 1989 & 1994 & 1999 & 2002 \\
\hline \multicolumn{5}{|l|}{ Gastos em P\&D } \\
\hline Total & 59.925 & 91.574 & 126.291 & (1) \\
\hline Realizados nas Filiais & 7.048 & 11.877 & 18.144 & 21.151 \\
\hline \multicolumn{5}{|l|}{ Vendas } \\
\hline Total & 3.329 .443 & 3.990 .013 & 5.975 .478 & 6.426 .628 \\
\hline Realizado pelas Filiais & 1.019 .966 & 1.435 .901 & 2.218 .945 & 2.548 .625 \\
\hline Participação das Filiais no Total (\%) & 30,6 & 36,0 & 37,1 & 39,7 \\
\hline
\end{tabular}

Fonte: Bureou of Economic Analisys. Elaboração NEIT/IEL/Unicamp. (1) Dado não disponivel. 
o aumento da importância das atividades das filiais ocorreu nos dois indicadores e com ritmo parecido. Porém, fica evidente que a internacionalização da P\&D ainda é muito mais concentrada no mercado norte-americano do que as vendas.

Enquanto a participação dos gastos de $\mathrm{P} \& \mathrm{D}$ realizados no exterior através das filiais aumentou de $11,8 \%$ do total em 1989 para 14,3\% em 1999, nas vendas essa proporção cresceu de $30,6 \%$ para $37,1 \%$, no mesmo período.

Considerando a distribuição dos gastos em P\&D entre as filiais, a Tabela 2 indica o aumento da importância relativa dos países em desenvolvimento, que em 1989 respondiam por apenas $5,2 \%$ do total e atingiram $15,1 \% \mathrm{em}$ 1999. Entre os países em desenvolvimento, comparando o desempenho da América Latina e da Ásia, observa-se que até 1994 os dois grupos conseguiram aumentar sua participação, mas com a Ásia já apresentando taxa de crescimento maior. Ainda assim, nesse ano, a participação das filiais da América Latina ainda era superior. Entre 1994 e 1999, verifica-se perda de importância relativa da América Latina, que teve sua participação reduzida para 3,4\% do total, enquanto a Ásia continuou sua trajetória de crescimento, atingindo 7,7\% do total. Os dados para 2002 só estão disponíveis para a Ásia e mostram que a região representou nesse ano $10 \%$ do total.

Portanto, pelo menos para as ETNs dos Estados Unidos, a internacionalização dos gastos em P\&D não ficou restrita às atividades dos países centrais, deslocando-se em direção àqueles em desenvolvimento, embora em ritmo ainda relativamente lento. Entretanto, esse foi um movimento concentrado nos países em desenvolvimento da Ásia, em especial na segunda metade da década de 90.

Os dados da Tabela 3 detalham as informações anteriores, mostrando os principais países em cada região. Analisando o caso do Brasil, observa-se que, em 1989 e 1994, as filiais instaladas no país representaram a maior partici- pação entre os países em desenvolvimento analisados. Em 1989, os gastos em P\&D das filiais brasileiras chegaram a representar $25 \%$ do total realizado nos países em desenvolvimento, diminuindo para cerca de $20 \%$ em 1994 e $10 \%$ em 1999. Em relação ao total dos países, a participação brasileira caiu de 2\% em 1994 para 1,4\% em 2002.

Fica evidente, portanto, a perda de importância relativa das filiais brasileiras nas atividades tecnológicas internacionais das grandes empresas norte-americanas. Ainda assim, o Brasil continua sendo o país com maior importância relativa na América Latina, posicionando-se ainda à frente do México, mesmo considerando o aumento da importância das filiais mexicanas em termos de vendas, ${ }^{2}$ quase duas vezes maior do que a participação brasileira. As demais economias da América Latina possuem representatividade menor ficando bem abaixo de Brasil e México.

Comparando-se com os países em desenvolvimento da Ásia, o contraste com a América Latina é evidente, uma vez que, nos primeiros, a tendência de aumento de participação ocorre em praticamente todos os países. Merecem destaque a evolução das filiais instaladas na China e em Cingapura, que passaram a ser os dois centros com maior importância entre todos os países em desenvolvimento analisados, além da Malásia, que, embora não tenha dados para 2002, apresentou crescimento acelerado entre 1989 e 1999.

É interessante também comparar, na Tabela 4, a participação das filiais de cada país no total de gastos em P\&D e nas vendas. Enquanto os países da América Latina são, invariavelmente, mercados mais importantes do que centros de $\mathrm{P} \& \mathrm{D}$, nos países asiáticos a disparidade entre participação nas vendas e em P\&D não é tão grande. Alguns países até mesmo se destacam por apresentarem maior importância relativa para a atividade de $P \& D$ do que para vendas.

TABELA 2

Participação dos Países em Desenvolvimento no Total de Gastos de P\&D das Filiais de ETN dos Estados Unidos Países em Desenvolvimento, América Latina e Ásia - 1989-2002

\begin{tabular}{lcccr} 
& & & Em porcentagem \\
\hline Região & 1989 & 1994 & 1999 & 2002 \\
\hline Países em Desenvolvimento & 5,2 & 10,3 & 15,1 & - \\
América Latina & 2,2 & 4,0 & 3,4 & $(1)$ \\
Ásia & 1,1 & 3,4 & 7,7 & 10,0 \\
\hline
\end{tabular}

Fonte: Bureou of Economic Analisys. Elaboração NEIT/IE/Unicamp. (1) Dado não disponivel. 
TABELA 3

Participação no Total de Gastos de P\&D das Filiais de ETNs dos Estados Unidos, segundo Países em Desenvolvimento América Latina e Ásia - 1989-2002

\begin{tabular}{|c|c|c|c|c|}
\hline Países em Desenvolvimento & 1989 & 1994 & 1999 & 2002 \\
\hline América Latina & 2,2 & 4,0 & 3,4 & (1) \\
\hline Argentina & 0,1 & 0,2 & 0,1 & 0,1 \\
\hline Brasil & 1,3 & 2,0 & 1,6 & 1,4 \\
\hline Chile & 0,01 & 0,02 & 0,02 & 0,03 \\
\hline Venezuela & 0,1 & 0,1 & 0,2 & 0,2 \\
\hline México & 0,5 & 1,5 & 1,3 & 1,3 \\
\hline Ásia & 1,1 & 3,4 & 7,7 & 10,0 \\
\hline China & 0,0 & 0,1 & 1,8 & 3,1 \\
\hline Hong Kong & 0,1 & 0,4 & 1,2 & (1) \\
\hline Índia & 0,03 & 0,04 & 0,1 & 0,4 \\
\hline Coréia & 0,1 & 0,1 & 0,6 & 0,8 \\
\hline Malásia & 0,04 & 0,2 & 0,9 & (1) \\
\hline Filipinas & 0,1 & 0,1 & 0,2 & 0,2 \\
\hline Cingapura & 0,4 & 1,4 & 2,3 & 2,8 \\
\hline Taiwan & 0,3 & 0,9 & 0,7 & 0,3 \\
\hline Tailândia & 0,01 & 0,03 & 0,04 & 0,1 \\
\hline
\end{tabular}

Fonte: Bureou of Economic Analisys. Elaboração NEIT/IEL/Unicamp. (1) Dado não disponivel.

TABELA 4

Comparação entre a Participação no Total de Gastos de P\&D e no Total de Vendas das Filiais de ETN dos Estados Unidos, segundo Países em Desenvolvimento América Latina e Ásia - 2002

\begin{tabular}{|c|c|c|c|}
\hline Países em Desenvolvimento & $\begin{array}{l}\text { Participação no Total } \\
\text { de Gastos de P\&D } \\
\text { (A) }\end{array}$ & $\begin{array}{l}\text { Participação no Total } \\
\text { de Vendas } \\
\text { (B) }\end{array}$ & $A / B$ \\
\hline América Latina & (1) & 12,1 & (1) \\
\hline Argentina & 0,1 & 0,7 & 14,3 \\
\hline Brasil & 1,4 & 2,3 & 60,9 \\
\hline Chile & 0,03 & 0,3 & 10,0 \\
\hline Venezuela & 0,2 & 0,5 & 40,0 \\
\hline México & 1,3 & 4,4 & 29,5 \\
\hline Ásia & 10,0 & 12,3 & 81,3 \\
\hline China & 3,1 & 1,7 & 182,4 \\
\hline Hong Kong & 2,1 & 1,2 & 55,4 \\
\hline Índia & 0,4 & 0,3 & 133,3 \\
\hline Coréia & 0,8 & 0,7 & 114,3 \\
\hline Malásia (2) & 1,0 & 0,9 & 90,1 \\
\hline Filipinas & 0,2 & 0,4 & 50,0 \\
\hline Cingapura & 2,8 & 3,7 & 75,7 \\
\hline Taiwan & 0,3 & 0,9 & 33,3 \\
\hline Tailândia & 0,1 & 0,8 & 12,5 \\
\hline
\end{tabular}

Fonte: Bureou of Economic Analisys. Elaboração NEIT/IEL/Unicamp.

(1) Dado não disponivel.

(2) Dados de 1999 
Nesta situação encontram-se Índia, Coréia do Sul e China. O caso da China, em especial, chama atenção, uma vez que as filiais chinesas, em 2002, representavam 1,7\% das vendas de todas as filiais, mas $3,1 \%$ dos gastos em $\mathrm{P} \& \mathrm{D}$, ou seja, a participação nos gastos em $\mathrm{P} \& \mathrm{D}$ chega a ser quase duas vezes maior do que nas vendas. Comparando-se com o Brasil, a participação nos gastos em P\&D representa $60,9 \%$ daquela referente às vendas. Em 2002, portanto, o Brasil era ainda um centro de produção e vendas mais importante do que a China, mas com uma importância para as atividades tecnológicas muito menor.

Em relação aos demais países, o Brasil está na primeira posição na América Latina e supera ainda alguns países na Ásia, como Tailândia, Taiwan e Filipinas, mas fica abaixo de outros, como Cingapura e Malásia (dados de 1999).

Outro indicador que revela a maior importância relativa das atividades inovativas nos países em desenvolvimento da Ásia do que nos da América Latina é o dispêndio de
P\&D em relação às vendas. De acordo com a Tabela 5, no total de suas operações mundiais, inclusive na matriz, a proporção de gastos em $\mathrm{P} \& \mathrm{D}$ em relação às vendas das ETNs dos EUA aumentou de 1,8\% em 1989 para 2,3\% em 1994, reduzindo-se um pouco em 1999, quando atingiu $2,1 \%$. Considerando esse mesmo indicador para todas as operações das filiais, o índice chegou a $0,7 \%$ em 1989, subindo para $0,8 \%$ em 1994 e mantendo-se nesse patamar em 1999 e 2002.

Nas filiais instaladas nos países desenvolvidos, como seria de se esperar, a intensidade do esforço inovativo é maior do que a média para o total das filiais, aumentando de $0,8 \%$ para $1 \%$ entre 1994 e 1999 . No conjunto dos países em desenvolvimento, o mesmo indicador apresentou tendência de aumento e passou de $0,2 \%$ em 1989 para $0,3 \%$ em 1994 e $0,4 \%$ em 1999, reduzindo, portanto, a diferença em relação ao nível observado nos países desenvolvidos.

TABELA 5

Proporção dos Gastos em P\&D sobre Vendas Total e nas Filiais no Exterior das ETNs dos Estados Unidos, segundo Países em Desenvolvimento América Latina e Ásia - 1989-2002

\begin{tabular}{|c|c|c|c|c|}
\hline & & & & \\
\hline Países em Desenvolvimento & 1989 & 1994 & 1999 & 2002 \\
\hline Total das ETNs & 1,8 & 2,3 & 2,1 & (1) \\
\hline Total das Filiais & 0,7 & 0,8 & 0,8 & 0,8 \\
\hline Países Desenvolvidos & 0,8 & 1,0 & 1,0 & (1) \\
\hline Países em Desenvolvimento & 0,2 & 0,3 & 0,4 & (1) \\
\hline América Latina & 0,2 & 0,4 & 0,2 & (1) \\
\hline Argentina & 0,2 & 0,2 & 0,1 & 0,1 \\
\hline Brasil & 0,3 & 0,7 & 0,5 & 0,5 \\
\hline Chile & 0,05 & 0,04 & 0,04 & 0,05 \\
\hline Venezuela & 0,3 & 0,3 & 0,4 & 0,3 \\
\hline México & 0,2 & 0,5 & 0,3 & 0,3 \\
\hline Ásia & 0,1 & 0,3 & 0,6 & 0,7 \\
\hline China & 0,0 & 0,2 & 1,6 & 1,5 \\
\hline Hong Kong & 0,1 & 0,2 & 0,5 & (1) \\
\hline Índia & 0,6 & 0,5 & 0,4 & 1,0 \\
\hline Coréia & 0,2 & 0,3 & 0,9 & 0,9 \\
\hline Malásia & 0,1 & 0,2 & 0,7 & (1) \\
\hline Filipinas & 0,2 & 0,3 & 0,4 & 0,5 \\
\hline Cingapura & 0,2 & 0,4 & 0,5 & 0,6 \\
\hline Taiwan & 0,3 & 0,8 & 0,7 & 0,3 \\
\hline Tailândia & 0,02 & 0,04 & 0,05 & 0,1 \\
\hline
\end{tabular}

Fonte: Bureou of Economic Analisys. Elaboração NEIT/IEL/Unicamp. (1) Dado não disponivel. 
Analisando-se os dados por região, verifica-se que, na América Latina, a proporção de gastos em P\&D teve um aumento importante entre 1989 e 1994, subindo de 0,2\% para $0,4 \%$, mas voltou a diminuir para $0,2 \%$ em 1999 . Enquanto no final da década de 80 o indicador estava no mesmo patamar da média das filiais instaladas em países em desenvolvimento, no final da década de 90 a proporção na América Latina era bem menor.

$\mathrm{Na}$ economia brasileira, o aumento na proporção de gastos em P\&D sobre vendas das filiais foi ainda mais acentuado entre 1989 e 1994 , passando de $0,3 \%$ para $0,7 \%$. Nesse último ano, entre os países discriminados na tabela, o Brasil apresentou o segundo indicador mais elevado, ficando atrás apenas de Taiwan. Entretanto, entre 1994 e 1999 , a proporção voltou a se reduzir, atingindo $0,5 \%$, patamar que se manteve em 2002.

Nos demais países da América Latina, a proporção esteve sempre abaixo da verificada na economia brasileira. Em 2002, as filiais da Argentina e do Chile atingiram 0,1\% e as do México e Venezuela chegaram a $0,3 \%$.

Já na Ásia a proporção de gastos em P\&D sobre vendas apresentou tendência de aumento, principalmente a partir de 1994, confirmando o fato de que efetivamente alguns países asiáticos conseguiram atrair importantes investimentos voltados para o desenvolvimento tecnológico. Analisados em conjunto, os países em desenvolvimento da Ásia experimentaram uma elevação contínua da intensidade de P\&D no período analisado: de $0,1 \%$ em 1989 , o indicador passou para $0,3 \% \mathrm{em} 1994,0,6 \%$ em 1999 e $0,7 \%$ em 2002.

Novamente, destaca-se o caso da China, que de $0,2 \%$, em 1994, atingiu 1,6\% em 1999, patamar inclusive superior ao verificado para o conjunto dos países desenvolvidos. Em 2002, o indicador se reduziu um pouco, ficando em 1,5\%.

A Índia também merece destaque, uma vez que, desde o início do período analisado, as filiais instaladas nesse país sempre tiveram uma proporção de gastos em $P \& D$ sobre vendas muito superior aos demais países da região. Apesar de uma queda de $0,6 \%$ para $0,4 \%$, entre 1989 e 1999 , em $2002 \mathrm{o}$ indicador atingiu $1 \%$.

Outros dois países asiáticos importantes em termos de intensidade de P\&D são Coréia e Malásia. No primeiro, a proporção foi de $0,2 \% \mathrm{em} 1989$, aumentando para $0,9 \% \mathrm{em}$ 1999 e permanecendo estável em 2002 nesse mesmo nível. No caso da Malásia, a elevação foi de $0,1 \%$ em 1989 para 0,7\% em 1999 .

Em resumo, observa-se que as grandes ETNs dos Estados Unidos aumentaram os gastos em P\&D no exterior, internacionalizando suas atividades tecnológicas em ritmo similar ao verificado para as vendas. Porém, o mais importante é que, nessa internacionalização, os países em desenvolvimento ganharam importância em relação aos desenvolvidos. Embora estes continuem respondendo pela maioria dos gastos em P\&D realizados fora dos Estados Unidos, é nítido o aumento da importância dos primeiros.

De certa maneira, esse fato pode refutar a conclusão de Cassiolato et al. (2001), de que o processo de internacionalização permanece restrito à tríade. Apesar disso, os dados analisados mostram a seletividade das ETNs na escolha de onde localizar as atividades de $\mathrm{P} \& \mathrm{D}$ e a posição desigual entre os próprios países em desenvolvimento. Num primeiro nível, fica evidente a diferença que se estruturou ao longo da década de 90 , em especial na sua segunda metade, entre os países da Ásia e da América Latina. O aumento da importância relativa da Ásia e a redução da participação da América Latina aparece em todos os indicadores analisados.

Com certeza, o aumento da importância da Ásia enquanto região preferencial de produção, principalmente de produtos associados ao complexo eletrônico/tecnologia de informação, teve peso importante nesse processo. ${ }^{3}$ Entretanto, é válido observar que, mesmo na Ásia, o movimento de aumento na importância nas atividades de P\&D não foi uniforme, permanecendo restrito a alguns países.

\section{CONSIDERAÇÕES FINAIS}

As informações analisadas neste trabalho mostram que, apesar de ainda manterem uma grande parte das atividades de P\&D no exterior concentrada nos países centrais, as multinacionais americanas têm aumentado os gastos tecnológicos nas filiais de países em desenvolvimento.

Observa-se, entretanto, um movimento bastante seletivo, com a concentração de atividades nos países em desenvolvimento da Ásia e, mesmo dentro desta região, em alguns poucos países, que conseguiram não apenas aumentar a participação nos gastos de P\&D das ETNs norteamericanas, mas também apresentar uma relação dispêndio de $\mathrm{P} \& \mathrm{D} / \mathrm{vendas}$ em níveis elevados e em patamares semelhantes ao observado nos países centrais.

O traço comum entre os países que demonstraram essa capacidade, destacando-se China, Coréia, Malásia, Cingapura e Índia, é a adoção de políticas tecnológicas ativas voltadas para criação de vantagens locacionais importantes para as atividades de elevado conteúdo tecnológico (qualificação de mão-de-obra, educação técnica e 
superior, suporte à pesquisa básica, financiamento e incentivos às atividades de $\mathrm{P} \& \mathrm{D}$ ), combinada com políticas de investimento seletivas, estruturadas com o objetivo de elevar o conteúdo tecnológico das atividades realizadas pelas filiais estrangeiras e aumentar o grau de complementaridade e integração com empresas e instituições locais (UNCTAD, 2002; LALL, 2000; 2003).

Dessa perspectiva, e comparando com a situação da América Latina, o trabalho de Katz (2001) ressalta que as reformas estruturais implementadas nessa região, na década de 90, assentadas sobre a abertura comercial, liberalização dos fluxos de capitais, privatizações e redução do poder de atuação do setor público, embora tenham tido impactos positivos sobre a modernização e eficiência (estática) do sistema produtivo, resultaram em redução dos esforços tecnológicos internos, tanto de empresas nacionais como daquelas transnacionais. Em primeiro lugar, a possibilidade de contar com insumos e bens de capital importados significou a substituição dos esforços tecnológicos das empresas anteriormente operando no mercado local por tecnologia incorporada diretamente nos bens importados. Do ponto de vista das ETNs, o novo padrão de utilização de tecnologia, mais convergente com os padrões internacionais, significou a redução dos esforços voltados para adaptação de produtos e processos ao mercado local. Em segundo lugar, a privatização de empresas públicas de infra-estrutura, em especial de energia e telecomunicações, foi acompanhada da desmobilização dos departamentos de P\&D e engenharia construídos durante a fase anterior. Por fim, os gastos na infra-estrutura de Ciência e Tecnologia, que nos países da América Latina sempre estiveram a cargo do Estado, sofreram impacto de sucessivos processos de corte de recursos em razão da necessidade de ajustes fiscais.

Pode-se adicionar a esses fatores a política direcionada para o investimento estrangeiro, que, ao contrário do verificado nos países em desenvolvimento da Ásia, não se preocupou em criar mecanismos voltados para aumento das atividades tecnológicas das filiais instaladas ou das novas entrantes no boom recente de IDE. Em vez de uma política seletiva em termos setoriais ou focada em atividades mais intensivas em tecnologia, os países da América Latina tiveram, em geral, uma política horizontal, em que a principal preocupação era retirar as restrições existentes ao IDE e à atuação das empresas estrangeiras e eliminar as regulamentações para remessas de lucros.

Analisando especificamente o caso do Brasil, os dados revelam a perda de posição relativa das filiais brasileiras na distribuição internacional de gastos em P\&D das multinacionais norte-americanas. Embora permaneça como o país na América Latina onde as filiais mais gastam em P\&D, a participação é muito menor do que a verificada nas vendas.

O recente boom de investimento estrangeiro ocorrido na década de 90 não alterou o papel das filiais brasileiras, que permaneceram tendo uma função restrita em termos de envolvimento em atividades de P\&D com maior densidade. De acordo com o trabalho de Araújo (2004), no final da década de 90, as filiais estrangeiras, apesar de serem mais inovadoras, em média gastavam menos em P\&D do que as empresas nacionais, o que evidenciaria que as atividades tecnológicas continuariam tendo uma função de adaptação às condições locais.

A vasta presença de filiais de grandes empresas transnacionais no Brasil, líderes mundiais em seus setores de atuação, com intensa atividade inovativa globalmente, continua, por enquanto, sendo um potencial de transferência de tecnologia que permanece pouco aproveitado. Com certeza as filiais operando no Brasil poderiam ter um papel muito mais relevante no desenvolvimento tecnológico e na geração de spillovers capazes de aumentar o grau de desenvolvimento da economia. Entretanto, essa não é uma tarefa trivial, já que, como ressaltado, a globalização das atividades de P\&D, embora crescente, vem ocorrendo de maneira muito mais seletiva, exigindo vantagens de localização relacionadas à infra-estrutura de ciência e tecnologia e qualificação de mão-de-obra, além de capacidade do setor público de coordenar ações no sentido de atrair investimentos ou estimular as ETNs já presentes a realizarem atividades ou funções corporativas com maior interação com o sistema nacional de inovação e com maior capacidade de geração de externalidades. Essa é uma tarefa que não foi realizada pelo Brasil no último ciclo de investimentos estrangeiros, e que permanece como desafio para esse início de século.

\section{NOTAS}

O autor agradece a ajuda prestada pelo auxiliar de pesquisa e bolsista Raphael Cega (Pibic do CNPq), pelo auxílio na organização dos dados deste artigo.

1. Na terminologia de Hirschey e Caves (1981), essas seriam as forças centrípetas e centrífugas, respectivamente. 
2. De uma participação nas vendas de 1,6\%, em 1989, o México aumentou para 2,7\% em 1994 e, após a integração com a economia norte-americana por intermédio do Nafta, atingiu 4,4\% em 2002. Ver Boletim Neit, n. 6.

3. Ver Boletim Neit n. 6, para uma análise detalhada da distribuição geográfica das atividades das filiais norte-americanas.

\section{REFERÊNCIAS BIBLIOGRÁFICAS}

ARAÚJO, R. D. Desempenho inovador e comportamento tecnológico das firmas domésticas e transnacionais no final da década de 90. 2004. Dissertação de Mestrado - IE/Unicamp, Campinas, 2004.

BOLETIM NEIT. Campinas: Unicamp, n. 6. Disponível em: <http:// www.eco.unicamp.br/Neit/boletim.htm>.

BUREAU OF ECONOMIC ANALYSIS. US investment abroad: financial and operation data, vários anos.

CANTWELL, J.; JANNE, O. The role of multinational corporations and national states in the globalization of innovatory capacity: the european perspective. Technology Analysis \& Strategic Management, v. 12 , n. 2,2000 .

CASSIOLATO, J.E.; LASTRES, H.; SZAPIRO, M. e VARGAS, M.A. Local systems of innovation in Brazil, development and transnational corporation: a preliminary assesment based on empirical results of a research project. DRUID conference paper, 2001.

COUTINHO, L.; LAPLANE, M.; HIRATUKA, C. (Org.). Internacionalização e desenvolvimento da indústria no Brasil. São Paulo: Unesp, 2003.

DUNNING, J. Multinational enterprise and the global economy. London: Addison Wesley, 1993.

GERYBADZE, A.; REGER, G. Globalization of R\&D: recent changes in the managament of innovation in transnational corporations. Research Policy, v. 28, 1999.

HAGEDOORN, J. Inter-firm R\&D partnership: an overview of major trends and patterns since 1960. Research Policy, v. 31, 2002.

HIRSCHEY, R.C.; CAVES, R.E. Internationalisation of research and transfer of technology by multinational enterprise. Oxford Bulletin of Economic and Statistics, n. 42, 1981.
KATZ, J. Structural reforms and technological behavior. The sources and nature of technological change in Latin America in the 1990s. Research Policy, v. 30, 2001.

LALL, S. Reinventing industrial strategy: the role of government policy in building industrial competitiveness. 2003. Mimeografado. (Texto preparado para o Grupo Intergovernamental de questões monetárias e desenvolvimento do G-24).

. Export performance technological upgrading and foreign direct investment strategies in the Asian newly industrializing economies with special reference to Singapur. Desarollo Productivo. Cepal, n. 88, 2000.

LAPLANE, M. F.; SARTI, F.; HIRATUKA, C.; SABBATINI, R. El caso brasileño. In: CHUDNOVSKY, D. (Ed.). El boom de las inversiones extranjeras directas en el MERCOSUR. Buenos Aires: Siglo XXI, 2001.

LE BAS, C.; SIERRA, C. Location versus home country advantages in R\&D activities: some further results on multinationals locational strategies. Research Policy, v. 31, 2002.

NARULA, R.; ZANFEI, A. Globalisation of innovation: the role of multinational enterprise. DRUID working papers, n. 3-15, 2003.

PATEL, P.; VEGA, M. Patterns of internationalisation of corporate technology: location versus home country advantages. Research Policy, v. $28,1999$.

PEARCE, R. Descentrelised R\&D and strategic competitiviness: globalised approaches to generation and use of technology in multinational enterprises. Research Policy, v. 28, 1999.

UNCTAD. World investment report: TNCs and export competitiviness. Nova York: Nações Unidas, 2002.

Célio Hiratuka: Doutor em Economia pela Unicamp. Pesquisador do Núcleo de Economia Industrial e da Tecnologia da Unicamp. Professor da Facamp (celio@eco.unicamp.br).

Artigo recebido em 4 de março de 2005. Aprovado em 28 de abril de 2005. 